Pacific Journal of Mathematic 


\title{
AN ASYMPTOTIC ANALYSIS OF AN ODD ORDER LINEAR DIFFERENTIAL EQUATION
}

\author{
DAVID LOWELL LOVELADY
}

Let $q$ be a continuous function from $[0, \infty)$ to $(0, \infty)$, and let $n$ be a positive integer. With respect to the equation $u^{(2 n+1)}+q u=0$, we study the relationship between the existence of oscillatory solutions and the asymptotic behavior of nonoscillatory solutions.

There is no additional hypothesis on $q$ which will ensure that every solution of

$$
u^{(2 n+1)}+q u=0
$$

is oscillatory. In particular, it follows from a result of P. Hartman and A. Wintner [5] that there is a solution $u$ of (1) such that

$$
(-1)^{k} u^{(k)}(t)>0
$$

whenever $t \geqq 0$ and $0 \leqq k \leqq 2 n$. We shall call a solution of $u$ of (1) strongly decreasing if and only if there is $c \geqq 0$ such that (2) is true whenever $t \geqq c$ and $0 \leqq k \leqq 2 n$. Since we know that (1) has a strongly decreasing solution, the best result one can hope for in an oscillation theorem is that every eventually positive solution of (1) is strongly decreasing. G. V. Anan'eva and V. I. Balaganskii [1] (see also C. A. Swanson [7, p. 175]) have shown that if

$$
\int_{0}^{\infty} t^{2 n-1} q(t) d t=\infty,
$$

then every eventually positive solution of (1) is strongly decreasing. Our first result extends this.

THEOREM 1. If (3) fails and the second order equation

$$
w^{\prime \prime}(t)+\frac{1}{(2 n-2) !}\left(\int_{t}^{\infty}(s-t)^{2 n-2} q(s) d s\right) w(t)=0
$$

is oscillatory, then every eventually positive solution of (1) is strongly decreasing.

Although the conclusion of Theorem 1 limits the asymptotic behavior of nonoscillatory solutions of (1) (if $u$ is nonoscillatory then either $u$ or $-u$ is eventually positive), it does not in fact ensure the existence of oscillatory solutions. 
THEOREM 2. Suppose that every eventually positive solution of (1) is strongly decreasing. Then if $u$ is a solution of (1), and if any of $u, u^{\prime}, u^{\prime \prime}, \cdots, u^{(2 n)}$ has a zero in $[0, \infty], u$ is oscillatory.

CoROLlaRY 1. With the hypotheses of Theorem 2, the solution space $Q$ of (1) has a basis each member of which is oscillatory, and $Q$ has a 2n-dimensional subspace each member of which is oscillatory.

COROLlaRY 2. With the hypotheses of Theorem 1, the conclusions of Corollary 1 hold.

Finally, we offer a comparison theorem.

THEOREM 3. Suppose that $p$ is a continuous function from [0, $\infty)$ to $(0, \infty)$ with $p(t) \geqq q(t)$ whenever $t \geqq 0$. Suppose also that every eventually positive solution of (1) is strongly decreasing. Then every eventually positive solution of

$$
u^{(2 n+1)}+p u=0
$$

is strongly decreasing.

A. C. Lazer has shown [6, Theorem 1.2] that in the third order case the existence of a nontrivial oscillatory solution of (1) implies that every eventually positive solution of (1) is strongly decreasing. The following example shows that this is not true in general.

Example. Suppose $1<r<2$. Now

$$
r(r-1)(r-2)(r-3)(r-4)>(r+2)(r+1) r(r-1)(r-2),
$$

so $\alpha>\gamma$, where

$$
\alpha=\min \{r(r-1)(r-2)(r-3)(r-4): 1 \leqq r \leqq 2\}
$$

and

$$
\begin{aligned}
\gamma & =\min \{(r+2)(r+1) r(r-1)(r-2): 1 \leqq r \leqq 2\} \\
& =\min \{r(r-1)(r-2)(r-3)(r-4): 3 \leqq r \leqq 4\} .
\end{aligned}
$$

Let $n=2$, and, noting that $\alpha$ and $\gamma$ are negative, let $\beta$ be a positive number such that $\alpha>-\beta<\gamma$. Let $q$ be given by $q(t)=\beta(t+1)^{-5}$. The polynomial equation

$$
r(r-1)(r-2)(r-3)(r-4)+\beta=0
$$

has two complex roots, so (1) has nontrivial oscillatory solutions. On the other hand, (6) has a solution $r$ in the interval $(3,4)$, and $u$, 
given by $u(t)=(t+1)^{r}$, satisfies (1) and is not strongly decreasing. The example is complete.

Lemma. Suppose $u$ is a solution of $(1), c \geqq 0$, and $(-1)^{k} u^{(k)}(c)>$ 0 for $k=0, \cdots, 2 n$. Then (2) is true for $0 \leqq t \leqq c$ and $k=0, \cdots$, $2 n$.

Proof. Let $v$ be given on $[-c, 0]$ by $v(t)=u(-t)$. If $k=0$, $\cdots, 2 n+1$ then $v^{(k)}(t)=(-1)^{k} u^{(k)}(-t)$, so

$$
v^{(2 n+1)}(t)-q(-t) v(t)=0
$$

and $v^{(k)}(-c)>0$ for $-c \leqq t \leqq 0$ and $k=0, \cdots, 2 n$. Thus

$$
v(t)=v(-c)+\sum_{m=1}^{2 n} \frac{(t+c)^{m}}{m !} v^{(m)}(-c)+\int_{-c}^{t} \frac{(t-s)^{2 n}}{(2 n) !} q(-s) v(s) d s
$$

if $-c \leqq t \leqq 0$. But clearly the solution of $(7)$ is positive, so $v(t)>0$ if $-c \leqq t \leqq 0$. Now, if $k=0, \cdots, 2 n$ and $-c \leqq t \leqq 0$,

$$
\begin{aligned}
v^{(k)}(t)=v^{(k)}(-c) & +\sum_{m=k+1}^{2 n} \frac{(t+c)^{m-k}}{(m-k) !} v^{(m)}(-c) \\
& +\int_{-c}^{t} \frac{(t-s)^{2 n-k}}{(2 n-k) !} q(-s) v(s) d s,
\end{aligned}
$$

so $v^{(k)}(t)>0$, i.e., $(-1)^{k} u^{(k)}(-t)>0$. The proof is complete.

Proof of Theorem 1. Assume that (3) fails. We shall show that if there is an eventually positive solution of (1) which is not strongly decreasing then (4) is nonoscillatory. Let $u$ be an eventually positive solution of (1) which is not strongly decreasing. Find $a \geqq 0$ such that $u(t)>0$ if $t \geqq a$. Now $u^{(2 n+1)}<0$ on $[a, \infty)$, so $u^{(2 n)}$ is eventually one-signed. Since $u^{(2 n)}$ is eventually one-signed, $u^{(2 n-1)}$ is eventually one-signed. Continuing this, we see that there is $c \geqq a$ such that none of $u, u^{\prime}, \cdots, u^{(2 n)}$ has a zero in $[c, \infty)$. Let $j$ be the largest integer such that $u^{(i)}>0$ on $[c, \infty)$ if $i \leqq j$ (we write $u=u^{(0)}$ ). Note that $j \neq 2 n+1$. Now $u^{(j+1)}<0$ on $[c, \infty)$, so $u^{(j)}$ is bounded. Thus, if $j \leqq k \leqq 2 n, u^{(k)} u^{(k+1)}<0$ on $[c, \infty)$. But $u^{(2 n+1)}<0$, so if $j \leqq k \leqq 2 n$ then $u^{(k)}>0$ on $[c, \infty)$ if $k$ is even and $u^{(k)}<0$ on $[c, \infty)$ if $k$ is odd. Since $u^{(j+1)}<0$ (recall how $j$ was chosen), this says $j+1$ is odd and $j$ is even. By hypothesis, $j \neq 0$. Suppose $j<2 n$. Now

$$
-u^{(j+1)}(t)=\frac{1}{(2 n-j-1) !} \int_{t}^{\infty}(s-t)^{2 n-j-1} q(s) u(s) d s
$$

if $t \geqq c$. Also, $u^{(j-1)}$ is increasing on $[c, \infty)$ since $u^{(j)}>0$, so, if $s \geqq$ $t \geqq c$, 


$$
\begin{aligned}
u(s) & \geqq \frac{1}{(j-2) !} \int_{c}^{s}(s-\xi)^{j-2} u^{(j-1)}(\xi) d \xi \\
& \geqq \frac{1}{(j-2) !} \int_{t}^{s}(s-\xi)^{j-2} u^{(j-1)}(\xi) d \xi \\
& \geqq \frac{u^{(j-1)}(t)}{(j-2) !} \int_{t}^{s}(s-\xi)^{j-2} d \xi=\frac{u^{(j-1)}(t)}{(j-1) !}(s-t)^{j-1} .
\end{aligned}
$$

Since $(2 n-j-1) !(j-1) ! \leqq(2 n-2) !$, this says

$$
\begin{aligned}
-u^{(j+1)}(t) & \geqq \frac{u^{(j-1)}(t)}{(2 n-2) !} \int_{t}^{\infty}(s-t)^{2 n-2} q(s) d s, \\
u^{(j+1)}(t) / u^{(j-1)}(t) & \leqq-\frac{1}{(2 n-2) !} \int_{t}^{\infty}(s-t)^{2 n-2} q(s) d s
\end{aligned}
$$

if $t \geqq c$. Let $v$ be given on $[c, \infty)$ by $v=u^{(j)} / u^{(j-1)}$, and note that $v>0$ on $[c, \infty)$. Now if $t>c$,

$$
v^{\prime}(t)=u^{(j+1)}(t) / u^{(j-1)}(t)-v(t)^{2},
$$

so (8) says

$$
v^{\prime}(t)+v(t)^{2} \leqq-\frac{1}{(2 n-2) !} \int_{t}^{\infty}(s-t)^{2 n-2} q(s) d s .
$$

But a classical result of M. Bôcher [2], [3] (see also C. de la Vallée Poussin [8], A. Wintner [9], C. A. Swanson [7, Theorem 2.15, p. 63], and W. A. Coppel [4, Theorem 4, p. 6]) says that the existence of a positive solution of (9) implies that (4) is nonoscillatory. The proof is complete, if $j<2 n$.

Suppose $j=2 n$. Now

$$
\begin{aligned}
u^{(2 n)}(t) & \geqq \int_{t}^{\infty} q(s) u(s) d s \\
& \geqq \frac{1}{(2 n-2) !} \int_{t}^{\infty} q(s)\left(\int_{c}^{s}(s-\xi)^{2 n-2} u^{(2 n-1)}(\xi) d \xi\right) d s \\
& \geqq \frac{1}{(2 n-2) !} \int_{t}^{\infty} q(s)\left(\int_{t}^{s}(s-\xi)^{2 n-2} u^{(2 n-1)}(\xi) d \xi\right) d s
\end{aligned}
$$

if $t \geqq c$. But this and standard iteration methods say that there is a continuously differentiable function $w$ from $[c, \infty)$ to $\left[u^{(2 n-1)}(c), \infty\right)$ such that $w(c)=u^{(2 n-1)}(c)$ and

$$
w^{\prime}(t)=\frac{1}{(2 n-2) !} \int_{t}^{\infty} q(s)\left(\int_{t}^{s}(s-\xi)^{2 n-2} w(\xi) d \xi\right) d s
$$

if $t \geqq c$. But $w$ clearly satisfies (4) on $[c, \infty)$, and can be extended to a nonoscillatory solution of $(4)$ on $[0, \infty)$, so the proof is complete. 
Proof of Theorem 2. Let $u$ be a nonoscillatory solution of (1). If $u$ is eventually negative, we may replace $u$ by $-u$, so we assume that $u$ is eventually positive. Now there is $c \geqq 0$ such that (2) holds whenever $t \geqq c$ and $k=0, \cdots, 2 n$. Now our lemma says that if $k=0, \cdots, 2 n$ then $u^{(k)}$ has no zeroes in $[0, c]$ and thus has no zeros at all. The proof is complete.

Proof of Corollary 1. If $k$ is an integer in $[1,2 n+1]$, let $z_{k}$ be the solution of (1) such that $z_{k}^{(j)}(0)=0$ if $j \neq k-1$ and $z_{k}^{(k-1)}(0)=$ 1. Clearly $\left\{z_{1}, \cdots, z_{2 n+1}\right\}$ is a basis for $Q$, and Theorem 3 says that each $z_{k}$ is oscillatory. Also, if $u$ is in the $2 n$-dimensional subspace spanned by $\left\{z_{2}, \cdots, z_{2 n+1}\right\}$, then $u(0)=0$ so $u$ is oscillatory. The proof is complete.

Corollary 2 is now immediate from Theorem 2 and Corollary 1.

Proof of Theorem 3. We shall assume the existence of an eventually positive solution of (5) which is not strongly decreasing, and show the existence of an eventually positive solution of (1) which is not strongly decreasing. Let $v$ be an eventually positive solution of (5) which is not strongly decreasing. Let $c \geqq 0$ be such that none of $v, v^{\prime}, \cdots, v^{(2 n)}$ has a zero in $[c, \infty)$, and let $j$ be the largest integer such that $v^{(i)}>0$ on $[c, \infty)$ if $i \leqq j$. By hypothesis, $j \neq 0$, and we know that $j$ is even. Now

$$
v^{(j)}(t) \geqq \frac{1}{(2 n-j) !} \int_{t}^{\infty}(s-t)^{2 n-j} p(s) v(s) d s
$$

if $t \geqq c$, and

$$
v(t) \geqq v(c)+\frac{1}{(j-1) !} \int_{c}^{t}(t-s)^{j-1} v^{(j)}(s) d s
$$

if $t \geqq c$, so

$$
\begin{aligned}
v(t) & \geqq v(c)+\frac{1}{(j-1) !(2 n-j)} \int_{c}^{t}(t-s)^{j-1}\left(\int_{s}^{\infty}(\xi-s)^{2 n-j} p(\xi) v(\xi) d \xi\right) d s \\
& \geqq v(c)+\frac{1}{(j-1) !(2 n-j) !} \int_{c}^{t}(t-s)^{j-1}\left(\int_{s}^{\infty}(\xi-s)^{2 n-j} q(\xi) v(\xi) d \xi\right) d s
\end{aligned}
$$

if $t \geqq c$. Now (10) and standard iteration techniques say that there is a continuous function $u$ from $[c, \infty)$ to $[0, \infty)$ such that $u(t) \leqq v(t)$ whenever $t \geqq c$ and such that

$$
\begin{aligned}
u(t)= & v(c) \\
& +\frac{1}{(j-1) !(2 n-j) !} \int_{c}^{t}(t-s)^{j-1}\left(\int_{s}^{\infty}(\xi-s)^{2 n-j} q(\xi) u(\xi) d \xi\right) d s
\end{aligned}
$$


if $t \geqq c$. The fact that $u$ has only nonnegative values, together with (11), says $u(t) \geqq v(c)$ whenever $t \geqq c$; in particular, $u$ has no zeros in $[c, \infty)$. Differentiation of (11) yields that $u$ satisfies (1) on $[c, \infty)$, and $u^{\prime}>0$ on $(c, \infty)$, i.e., (2) is not true for $k=1$ and $t>c$. Clearly $u$ can be extended to a solution of (1) on $[0, \infty)$, and this solution is eventually positive but not strongly decreasing. The proof is complete.

\section{REFERENCES}

1. G. V. Anan'eva and V. I. Balaganskii, Oscillation of the solutions of certain differential equations of high order, Uspehi Mat. Nauk., 14 (85) (1959), 135-140.

2. M. Bôcher, Application of a method of d'Alembert to the proof of Sturm's theorems of comparison, Trans. Amer. Math. Soc., 1 (1900), 414-420.

3. - Nonoscillatory linear differential equations of the second order, Bull. Amer. Math. Soc., 7 (1900-01), 333-340.

4. W. A. Coppell, Disconjugacy, Lecture Notes in Mathematics $\$ 220$, Springer-Verlag, New York, 1971.

5. P. Hartman and A. Wintner, Linear differential and difference equations with monotone solutions, Amer. J. Math., 75 (1953), 731-743.

6. A. C. Lazer, The behavior of solutions of the differential equation $y^{\prime \prime \prime}+p(x) y^{\prime}+$ $q(x) y=0$, Pacific J. Math., 17 (1966), 435-466.

7. C. A. Swanson, Comparison and Oscillation Theory of Linear Differential Equations, Academic Press, New York, 1968.

8. C. de la Valée Poussin, Sur l'équation différentielle linéaire du second ordre, J. Math. Pures Appl., (9) 8 (1929), 125-144.

9. A. Wintner, On the nonexistence of conjugate points, Amer. J. Math., 73 (1951), 368-380.

Received October 29, 1974 and in revised form March 4, 1975.

The Florida State University 


\section{PACIFIC JOURNAL OF MATHEMATICS}

\section{EDITORS}

RICHARD ARENS (Managing Editor)

University of California

Los Angeles, California 90024

\section{J. DugundJI}

Department of Mathematics University of Southern California Los Angeles, California 90007

D. Gilbarg and J. Milgram

Stanford University

Stanford, California 94305
University of Washington Seattle, Washington 98105

\section{ASSOCIATE EDITORS}
E. F. BECKENBACH
B. H. NeumanN
F. WolF
K. YoShIDA

\section{SUPPORTING INSTITUTIONS}

\author{
UNIVERSITY OF SOUTHERN CALIFORNIA \\ STANFORD UNIVERSITY \\ UNIVERSITY OF TOKYO \\ UNIVERSITY OF UTAH \\ WASHINGTON STATE UNIVERSITY \\ UNIVERSITY OF WASHINGTON \\ $\stackrel{*}{*} \stackrel{*}{*} \stackrel{*}{ }{ }^{*}$ AMERICAN MATHEMATICAL SOCIETY
}

The Supporting Institutions listed above contribute to the cost of publication of this Journal, but they are not owners or publishers and have no responsibility for its content or policies.

Mathematical papers intended for publication in the Pacific Journal of Mathematics should be in typed form or offset-reproduced, (not dittoed), double spaced with large margins. Underline Greek letters in red, German in green, and script in blue. The first paragraph or two must be capable of being used separately as a synopsis of the entire paper. Items of the bibliography should not be cited there unless absolutely necessary, in which case they must be identified by author and Journal, rather than by item number. Manuscripts, in triplicate, may be sent to any one of the editors. Please classify according to the scheme of Math. Reviews, Index to Vol. 39. All other communications should be addressed to the managing editor, or Elaine Barth, University of California, Los Angeles, California, 90024.

The Pacific Journal of Mathematics expects the author's institution to pay page charges, and reserves the right to delay publication for nonpayment of charges in case of financial emergency.

100 reprints are provided free for each article, only if page charges have been substantially paid. Additional copies may be obtained at cost in multiples of 50 .

The Pacific Journal of Mathematics is issued monthly as of January 1966. Regular subscription rate: $\$ 72.00$ a year (6 Vols., 12 issues). Special rate: $\$ 36.00$ a year to individual members of supporting institutions.

Subscriptions, orders for back numbers, and changes of address should be sent to Pacific Journal of Mathematics, 103 Highland Boulevard, Berkeley, California, 94708.

\section{PUBLISHED BY PACIFIC JOURNAL OF MATHEMATICS, A NON-PROFIT CORPORATION}

Printed at Kokusai Bunken Insatsusha (International Academic Printing Co., Ltd.), 270, 3-chome Totsuka-cho, Shinjuku-ku, Tokyo 160, Japan.

\section{Copyright (C) 1975 by Pacific Journal of Mathematics} Manufactured and first issued in Japan 


\section{Pacific Journal of Mathematics}

\section{Vol. 57, No. $2 \quad$ February, 1975}

Norman Larrabee Alling, On Cauchy's theorem for real algebraic curves with boundary .......

Daniel D. Anderson, A remark on the lattice of ideals of a Prüfer domain ..................

Dennis Neal Barr and Peter D. Miletta, A necessary and sufficient condition for uniqueness of

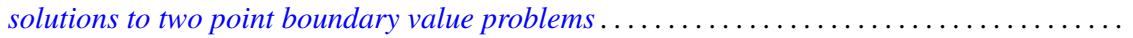

Ladislav Beran, On solvability of generalized orthomodular lattices . . . . . . . . . . ........

L. Carlitz, A three-term relation for some sums related to Dedekind sums . . . . . . . . . .....

Arthur Herbert Copeland, Jr. and Albert Oscar Shar, Images and pre-images of localization

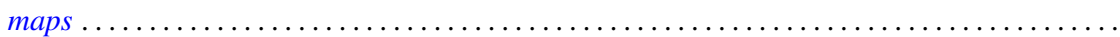

G. G. Dandapat, John L. Hunsucker and Carl Pomerance, Some new results on odd perfect

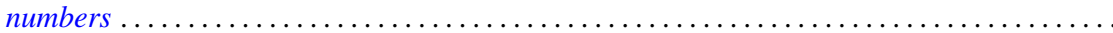

M. Edelstein and L. Keener, Characterizations of infinite-dimensional and nonreflexive

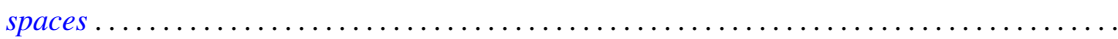

Francis James Flanigan, On Levi factors of derivation algebras and the radical embedding

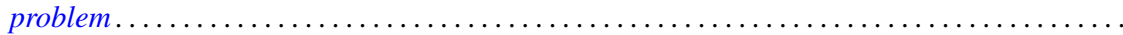

Harvey Friedman, Provable equality in primitive recursive arithmetic with and without

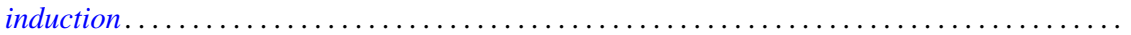

Joseph Braucher Fugate and Lee K. Mohler, The fixed point property for tree-like continua with

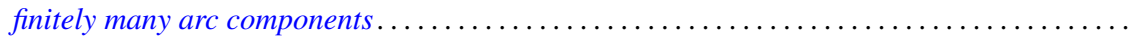

John Norman Ginsburg and Victor Harold Saks, Some applications of ultrafilters in

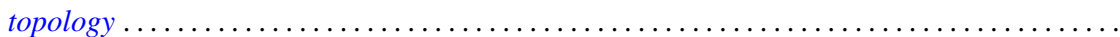

Arjun K. Gupta, Generalisation of a "square" functional equation .....................

Thomas Lee Hayden and Frank Jones Massey, Nonlinear holomorphic semigroups ..........

V. Kannan and Thekkedath Thrivikraman, Lattices of Hausdorff compactifications of a locally

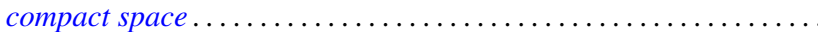

J. E. Kerlin and Wilfred Dennis Pepe, Norm decreasing homomorphisms between group

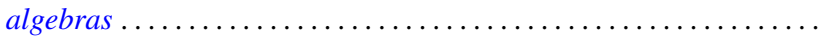

Young K. Kwon, Behavior of $\Phi$-bounded harmonic functions at the Wiener boundary ...

Richard Arthur Levaro, Projective quasi-coherent sheaves of modules .

Chung Lin, Rearranging Fourier transforms on groups...........................

David Lowell Lovelady, An asymptotic analysis of an odd order linear differential equation . . 4475

Jerry Malzan, On groups with a single involution .......................... 481

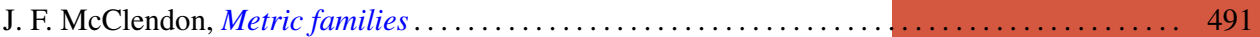

Carl Pomerance, On multiply perfect numbers with a special property .

Mohan S. Putcha and Adil Mohamed Yaqub, Polynomial constraints for finiteness of semisimple rings. .

Calvin R. Putnam, Hyponormal contractions and strong power convergence . . . . . . . . . 531

Douglas Conner Ravenel, Multiplicative operations in $\mathrm{BP} * \mathrm{BP} \ldots \ldots \ldots \ldots \ldots \ldots \ldots \ldots \ldots .539$

Judith Roitman, Attaining the spread at cardinals which are not strong limits . . . . . . . . . 545

Kazuyuki Saitô, Groups of *-automorphisms and invariant maps of von Neumann algebras . . . 553

Brian Kirkwood Schmidt, Homotopy invariance of contravariant functors acting on smooth

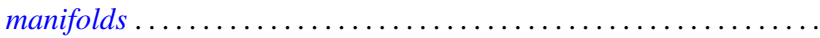

Kenneth Barry Stolarsky, The sum of the distances to $N$ points on a sphere.

Mark Lawrence Teply, Semiprime rings with the singular splitting property.

J. Pelham Thomas, Maximal connected Hausdorff spaces..............

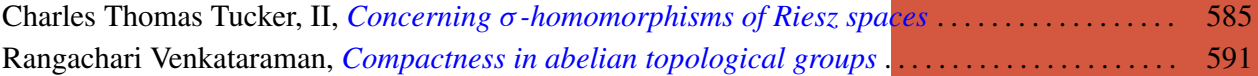

William Charles Waterhouse, Basically bounded functors and flat sheaves . . . . . . . . . . . 597

David Westreich, Bifurcation of operator equations with unbounded linearized part ......... 611

William Robin Zame, Extendibility, boundedness and sequential convergence in spaces of 